\title{
CIB-Concept for Probability Based Structural Fire Safety Design
}

\author{
L. TWILT and A. VROUWENVELDER \\ Institute TNO for Building Materials and Building Structures \\ Rijswijk, The Netherlands
}

\section{INTRODUCTION}

In most countries, the verification of the fire protection requirements gets much more attention than the requirements themselves. It is felt that this renders to a heavily unbalanced fire safety design. In view of this discrepancy, it has been decided within the Fire Commission of the Conseil International du Bâtiment (CIB-W14) to prepare a design concept which covers both afore mentioned aspects in an integrated way and which may serve as a framework for national design guides in this field.

Such an improved design concept should be based on clearly specified fire safety objectives and should recognize the contribution of structural design provisions to these objectives. Therefore structural requirements should be functional - i.e. refer to the expected performance of the structure and its members in an actual fire - so that verification of compliance can be done by an engineering design, comparable to the design for non-accidental situations. This calls for the use of analytical models for verification, as an alternative to experimental verification.

Moreover, structural requirements should allow for a certain equivalency of different design solutions comprising structural (passive) and operational (active) fire protection measures. This involves an assessment of the inherent degree of reliability, calling for a probabilistic approach.

Since, in 1980, this work was started by a CIB-W14 Workshop, based on earlier work, e.g. [1], [2], the following documents have been prepared:

- A Conceptional Approach Towards a Probability Based Design Guide on Structural Fire Safety [3]

- Design Guide on Structural Fire Safety [4].

In [3] the framework for a probabilistic design method on structural fire safety is outlined and a state of the art review of calculation models for verification is given. On basis of this report, in [4] operational rules for the assessment of buildings with respect to structural fire safety are presented. An important feature of this design procedure is, that not only one but a variety of assessment methods, with different levels of refinement is offered, allowing for an optimal balance between the verification. method on the one hand and the accuracy of available input data and the relevance of structural performance on the other hand. 
This paper decribes some of the principles of the CIB-design concept as well as its main limitations. A comparison will be made with a more traditional design concept for structural fire safety. To illustrate the benefit of the CIB design concept, a practical situation will be evaluated.

\section{PRINCIPLES AND LIMITATTONS OF THE CIB DESIGN CONCEPT}

Objective of fire protection is to limit:

- individual life risk and societal risk

- neighbouring property risk

- directly exposed property risk

to a level which is acceptable by society. Evaluation of directly exposed property risk is based on economic considerations only and should thus be the client's decision. More specificly, the aim of the design procedure is to confine fully developed fires within a compartment and to prevent local failure, leading to failure of the whole structural system (progressive collapse).

In order to achieve these aims, the design concept provides functional requirements for an adequate load bearing capacity of the structure and an adequate separating function of the structural components in case of a fire, severe enough to cause structural damage. The related limit states are:

(1) load bearing capacity

(2) thermal insulation

(3) integrity.

For verification, heat exposure models (H) as well as structural response models (S) are necessary. With respect to their level of refinement, different models of each type are presented:

\section{Heat Exposure Models}

(H1) a rise of temperature versus time according to IsO 834 , the duration of which is equal to the "required time of fire duration" expressed in building regulations and codes for the particular use of the building or fire compartment;

(H2) a rise of temperature versus time according to Iso 834 , the duration of which is approximated on the basis of the combustion and thermal conditions expected to prevail in the particular fire compartment;

(H3) a rise of temperature versus time expected in a compartment fire, directly related to the combustion and thermal conditions expected to prevail in the particular fire compartment.

\section{Structural Response Models}

(S1) the structure is considered as a number of individual structural members with simplified support and restraint conditions - the model can either be experimental or analytical;

(S2) the structure is considered as a number of sub-assemblies - analytical models prevail; 
(S3) the structure is analyzed as a whole, assuming fire exposure throughout the structure or only within an individual compartment.

Each combination of heat exposure model and structural response model, as an element of the matrix in Fig. 1, represents a particular design procedure. It is evident that not all models can be used in all possible combinations. The rule should be to provide a sensible relation in the levels of advancement of both mode1s. In the text in Fig. 1, reference is made to this aspect [5].

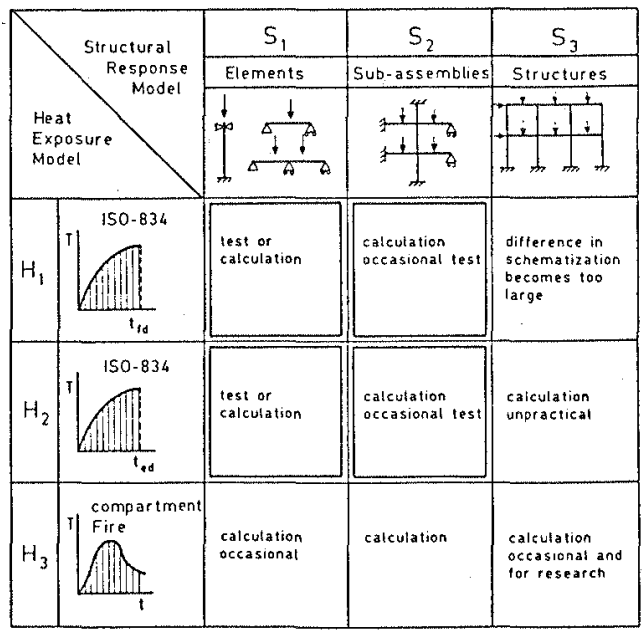

$t_{10}=$ required time of fire duration

FIGURE 1: Matrix of heat exposure and structural response models in sequence of improved schematization.

Taking the three above mentioned heat exposure models as a starting point, the CIB design concept distingulshes between the following assessment methods :

- Assessment Method 1: Method on the basis of ISO standard fire exposure. The design criterion is that the fire resistance, determined either by experiments or analytica11y, is equal to or exceeds the time of fire duration required by building regulations or codes. Reference for application: Model combinations H1-S1 or H1-S2.

- Assessment Method 2: Method on the basis of a standard fire exposure. The design criterion is that the fire resistance, determined either by experiments or analytically, is equal to or exceeds the equivalent time of fire exposure, a quantity which relates compartment (non-standard) fire exposure to the ISO standard fire. Reference for application: Model combination $\mathrm{H} 2-\mathrm{S} 1$ or $\mathrm{H} 2-\mathrm{S} 2$.

- Assessment Method 3: Method characterized by a direct analytical design on the basis of compartment (non-standard) fire exposure. Reference for application: Model combination H3-S1, H3-S2 or H3-S3.

In addition to the heat exposure models and the structural response models, also reliability models are to be defined, comprising - in principle - aspects such as: 
- Intrinsic randomess of design parameters and properties.

- Model uncertainties of the models for heat exposure and structural. response.

- Assessment of frequency, such as the probability of occurrence of a large fire, the effect of fire brigade actions, the reliabflity of sprinklers.

- Safety considerations from both human and economic point of view such as height, volume and occupancy of the bullding, availability of escape routes and rescue facilities as well as consequences of violating a limit state.

Verification requires the proof that - with a certain reliability and for a certain application - no relevant limit state conditions are failed. As a general design format the partial safety concept is used. For the three above introduced methods of assessment, design criteria are formulated dependent on their level of refinement/nature.

Assessment Method 1: The limit state is defined in the time domain. The design criterion reads:

$$
\left[\text { req. } t_{f}\right]-\left[\text { eva } 1 \cdot t_{f}\right] \leqslant 0
$$

wherein:

$\left[\mathrm{req} \cdot \mathrm{t}_{\mathrm{f}}\right]=$ required fire resistance according to a specified fire safety class;

[eval. $\left.t_{f}\right]=$ evaluated fire resistance.

The probabilistic aspects are implicitly dealt with by a proper cholce of the fire safety class.

Assessment Method 2: The limit state is defined in the time domain. The design criterion reads:

$$
t_{f} / \gamma_{f}-\gamma_{e} t_{e} \gamma_{n} \leqslant 0
$$

wherein:

$t_{f}=$ evaluated (characteristic) value of the fire resistance;

$t_{e}=$ (characteristic) value of the equivalent time of fire exposure calculated on basis of the fire load density $\left(=q_{f}\right)$ the ventilation conditions $(=w)$ and the thermal properties of the surrounding thermal properties $(=c) ; t_{e}=c \cdot w \cdot q_{f}$;

$\gamma_{f}=$ partial safety factor related to the fire resistance and for average reliability requirements;

$\gamma_{\mathrm{e}}=$ partial safety factor related to the equivalent time of fire exposure and for average reliability requirements;

$\gamma_{\mathrm{n}}=$ differentiation factor accounting for safety differentiation ( $Y_{n l} ; e . g$. height of bullding, number of persons involved) and frequency differentiation $\left(\gamma_{2} ;\right.$ e.g. envisaged alarm and sprinkler systems, force of fire brigade); $\gamma_{\mathrm{n}}=\gamma_{\mathrm{n} 1} \cdot \gamma_{\mathrm{n} 2}$.

with $\bar{\gamma}=\gamma_{e} \cdot \gamma_{f}$ equ. $\left(2^{a}\right)$ can be rewritten as:

$$
t_{f}>\bar{\gamma} \cdot t_{e} \cdot \gamma_{n}
$$

wherein: 
$\bar{\gamma}=$ global safety factor for average reliability requirements.

It is seen that in Assessment Method 2, the probabilistic aspects are accounted for explicitly.

Assessment method 3: The limit state is defined in either the mechanical strength domain (load bearing structures) or the temperature domain (separating structures). The design criteria are formulated in a way, analogue to the one specified for Assessment Method 2, on the understanding that $t_{f} / \gamma_{f}$ is replaced by the minimum design value of the ultimate load bearing capacity (resp.: maximum temperature at the unexposed side of the structure, acceptable with respect to insulation) and $t$. $Y$ is replaced by the design load (resp.: the highest design temperature at the unexposed side of the structure). Design values, again, may be calculated using the partial safety factor concept.

A most interesting feature of the ClB-approach is, that the partial safety factors and the differentiation factors, introduced in Assessment Method 2 and 3 are derived from target reliabilities and/or occurrence rates of fires over a probabilistic analysis, thus allowing for a differentiated and functional design. Therefore, in this paper, Assessment Methods 2 and 3 will be denoted as "advanced".

With regard to practical application, the $\mathrm{ClB}$-concept for structural fire safety design is subject to some limitations:

- A11 heat exposure models refer to a situation of post-flashover fires and a more or less uniform temperature distribution within the fire compartment. For very large fire compartments this assumption may be questionable.

- The verification of the limit state of integrity requires an experimental analysis. Especially in the case of Assessment Method 3, which is, due to its very nature focussed on analytical models, this may lead to some inconsistency.

- Regarding the probabilistic models, there is a lack of reliable data. This especially holds for the relations which describe the occurrence rates of fires. Also the target fallure probabilities are only determined in a global way, pending the availability of more extensive data and analysis of risk perception.

Despite these reservations, it is felt that the design guide should be used for practical applications, preferably together with more conventional design concepts. Thus the benefits and possibly the shortcomings of the new design concept will become more explicit.

\section{COMPARISON WITH A TRADITIONAL DESIGN CONCEPT}

As an example, the directives for structural fire safety design which are currently used in The Netherlands [6] w111 be reviewed and be compared with the CIB-concept.

In The Netherlands the fire safety requirements are primarily directed towards the limitation of individual life risk, societal risk and neighbouring property risk. To limit directly exposed property risk is principally outside the scope of the directives; consequently no explicit 
guidance in this respect is provided. The clB-concept does give such guidance, by differentiating with respect to target reliabilities.

Effectively, the Dutch concept for structural fire safety is to be considered as a rating system for bullding components. There are, practically spoken, four classes, defined by a minimum required fire resistance according to ISO-834: $30,60,90$ and 120 minutes. Classification is as follows: To start with, the effective time of fire exposure according to the Iso-standard fire, $t_{\text {eff, }}$ is determined by:

$$
t_{\text {eff }}=q_{t} \quad[\mathrm{~min}]
$$

wherein:

$q_{t}=$ the total fire load density due to building components and contents in the fire compartment [ $\mathrm{kg}$ wood $/ \mathrm{m}^{2}$ floor area].

The fire load density is determined as a representative value for the building type and occupancy under consideration. An individual assessment of the fire load is - as opposed to the suggestion in the CIB-concept normally not accepted. The effective fire duration (=teff) is transformed to the "required fire safety class" according to:

$\begin{aligned} 0<t_{\text {eff }} \leqslant 30: \text { min. fire resistance } & : 30 \mathrm{~min} . \\ 30<t_{\text {eff }} \leqslant 60: " \text { : } & \text { " } 60 \text { min. }\end{aligned}$

etc.

The CIB-approach is more flexible since - for Assessment Method 2 and 3 in principle continuous limit state functions are specified.

In the Dutch design concept as well as in the CIB approach, safety and frequency differentitation is dealt with separately.

As far as frequency differentiation is concerned, the Dutch method only gives explicit guidance for the risk reducing effect of the public fire brigade. It is assumed that the public fire brigade all over the country meets the same standard and that fires will be under control within 60 minutes after flash-over. This means that the effective fire duration according to equ. (3) will be limited to 60 minutes, irrespective of the actual fire load. The CIB-method differentiates with respect to public and residential fire brigade and/or sprinkler installation, on basis of the anticipated reduction of fire occurrence.

Regarding safety differentiation, the building height and the function of the structural components under consideration are main parameters in the Dutch design method. Specific rules are only given for a limited number of building categories, such as appartment buildings and hotels. In these cases, the required fire resistance following from the relevant value of the effective fire duration is increased by 30 minutes (= one safety class); if the height of the upper floor is more than a certain value (= $13 \mathrm{~m})$ above street level, the increase amounts 60 minutes (= two safety classes). The additional fire resistance is only required for the limit state of load bearing capacity and for main structural elements, i.e. those elements the failure of which may lead to progressive collapse. These aspects are also recognized in the CIB-concept, but are here - more consistently - expressed In terms of target failure probabilities.

Verification in the Dutch directives is on the level of Assessment Method 1 according to the CIB design concept (cf. equ. 1). 
It follows from the above comparison that the traditional (Dutch) design concept has some important features in common with (advanced) CIB-Assessment Method 2, e.g. limit states, idea of equivalent time of fire duration, idea of safety and frequency differentiation.

However, in the CIB-concept these aspects are evaluated in a consequent and deducible manner, whereas the traditional method gives global rules, mainly based on practical experience. Moreover, in the traditional method, a proper probabilistic basis is missing, reason why this method is essentially to be identified as a CIB-Assessment Method 1 approach.

In the next chapter some practical implementations of the use of either the traditional (Dutch) or the advanced CIB-methods will be reviewed.

\section{TMPLEMENTATIONS FOR PRACTICAL DESIGN - A CASE STUDY}

In Rotterdam, The Netherlands, a series of 4 similar police offices is under design. One of the options is a cube shape concept with dimensions of $12 \times 12 \times 12 \mathrm{~m}^{3}$. In this "cube", three floor levels are planned. Since there are no compartmentation walls inside the building, each floor is to be considered as one fire compartment with a floor area of $12 \times 12=144 \mathrm{~m}^{2}$. Per storey, in each of the four outer walls, three windows with dimensions $1.8 \times 1.8 \mathrm{~m}^{2}$ are situated as is shown in $\mathrm{Fig.} 2$.

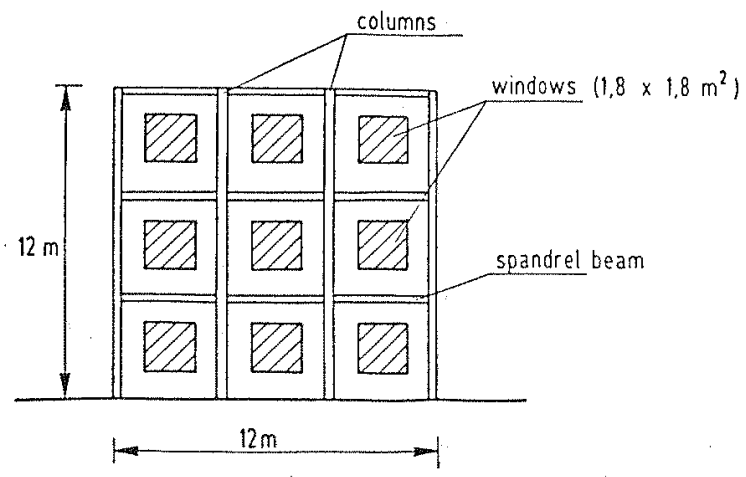

FIG. 2: Front view of the facade

For the main load bearing structure a three dimensional steel frame is planned, consisting of columns, spandrel beams and floor beams. A11 columns are outside the facade and between the windows. The same holds for the spandrel beams. Thus, the facade acts as a heat shield to protect the external steel work from a fire inside the building. The floors consist of reinforced concrete slabs, cased in situ and carried by the floor and spandrel beams. Apart from the window openings, the facades are of masonry.

A key element in the architectural concept is the application of bare external structural stee1. Protection of the internal steelwork - if necessary - is acceptable. For this reason and because the concrete floors and masonry facades are not critical, the following discussion will be focussed on the fire safety of the steel structure. 
In the traditional (Dutch) design concept, the actual fire conditions are ignored, and requirements - if any - are expressed solely in terms of fire resistance according to ISO 834 (standard fire conditions). The level of required fire resistance depends with equ. (3) on the total fire load density $q_{f}$. According to the Dutch regulations, the representative fire load density for offices amounts $60 \mathrm{~kg} / \mathrm{m}^{2}$. This value is based on Dutch statistics and corresponds roughly to the $80 \%$ fractile. Taking into account the additional 30 minutes for safety differentiation, it follows for the required fire resistance of the steel frame: $60+30=90$ minutes. The fire resistance of unprotected steel elements under common design loads is in the order of magnitude of 10 to 30 minutes. So, without detailed analysis it is clear that with bare (external) steel, the specified requirement cannot be met. As a direct consequence the whole design concept fails.

In view of this extreme important consequence, it is at hand to re-evaluate the design on basis of one of the advanced and thus more differentiated CIB-methods.

Assessment Method 2 seems to be an appropriate method for evaluating the requirement for the internal steelwork, since the related concept of equivalent fire duration is derived for ventilation controlled compartment fires in not too large compartments.

An evaluation on basis of Assessment Method 2, taking into account the same fire load statistics as in the afore mentioned analysis, renders a required fire resistance of 90 minutes under the following (main) conditions:

- tolerable annual failure probability $\left(p_{f}\right)=2 \times 10^{-6}$;

- annual probability of initial fires $(p): 0.5 \cdot 10^{-6}$. A, where A is the floor area of the fire compartment;

- reduction of the probability of a severe fire due to standard public fire brigade only $\left(\mathrm{p}_{1}\right): 10^{-1}$;

- safety differentiation factor to allow for the relative importance of the steel frame $\left(\gamma_{n 1}\right): 2.1$;

- reduction of the variable part of the fire load (m): 0.4, to allow for the effect of partial protection.

It is noted that the adopted rate of fire occurrence, $p$, as we11 as the reduction effect of the fire brigade action, $p_{1}$, are in 1ine with European data. The applied reduction factor $m$ on the variable fire load is obtained for conditions, which are representative for offices [7]. Calculation of the partial safety factors is based on $80 \%(20 \%)$ fractiles for $t_{f}$ and $t_{e}$ while variation coefficients as suggested in [4] are taken into account. The resulting average reliability level may, in view of the choice of $p_{f}$, be associated with a situation in which structural collapse involves low personal risk and medium economic loss [8]. By introducing the safety differentiation factor $\gamma_{01}=2.1$, the average reliability is increased by roughly one to two orders ${ }^{n}$ of magnitude.

Thus - a posteriori - a functional motivation is provided for the $90 \mathrm{minu}$ tes requirement, which follows from the traditional (Dutch) design method. It will be clear, that the above results do not proof whether the 90 minutes requirement is "right" or "wrong". They give however a basis for rational discussion. Other options can easily be evaluated. As far as the internal steelwork in the considered design is concerned, such a discussion is not of much help: Also a decrease of the required fire resistance to, say, 60 minutes, would mean that the steel is to be protected. 
For the external steelwork, however, the 90 minutes requirement should not be analysed on basis of Assessment Method 2 due to the specific type of fire exposure, which is not accounted for in the concept of equivalent fire duration. In this case an Assessment Method 3 analysis is necessary. Such an analysis is carried out, using the calculation model for fire exposed bare external steelwork, described in [9]. In this model, rules are given to calculate the heat transfer to the steel coming from both the internal fire, radiating through the windows and the emerging flames. As a result, steady state steel temperatures are determined, which may be considered as upper bound values of the steel temperatures which will be attained during a real fire. Geometry of the fire compartment, wind conditions and fire load density are main parameters.

For the limit state expressed in the temperature domain, design verification is for instance accomplished by ensuring that:

$$
T_{c} / \gamma_{c}-T_{s}\left(\gamma_{s} \gamma_{n} q_{f}\right) \geqslant 0
$$

wherein:

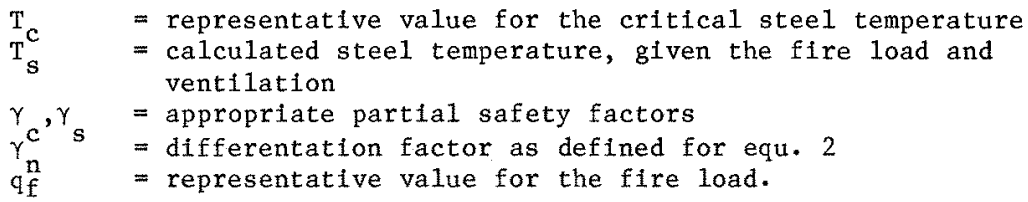

The CIB design gulde does not provide fully operational guidance for the evaluation of equ. (4). For practical application the following reasoning wi11, however, suffice: For a certain situation defined by building geometry, type of wind conditions (viz. through draught or no through draught) etc., the fire load density $q_{f}$ is the main variable for $T_{s}$. The relation between $\mathrm{q}_{f}$ and $\mathrm{T}_{\mathrm{s}}$ is - for the consfdered building design - presented in Fig. 3 for both the columns and the spandrel beams.

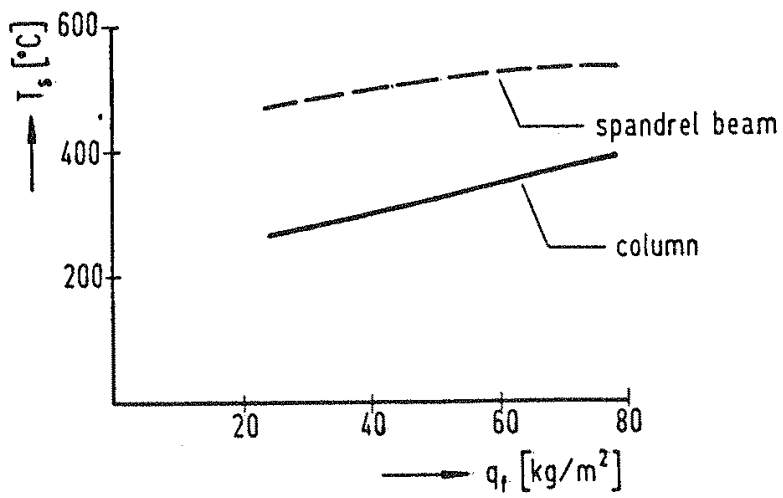

FIG 3: Relation between the fire load density $\left(q_{f}\right)$ and the calculated steel temperature $\left(\mathrm{T}_{\mathrm{S}}\right)$ of the columns and the spandrel beams. 
Note that the influence of $q_{f}$ on the maximum attained steel temperature is rather insignificant. When $\mathrm{T}^{\mathrm{i}}$ is determined over a certain design range of $q_{f}$, the choice of this design value $\left(=q_{f d}\right)$ will, therefore, not be very critical. It is suggested to choose, as a rough approximation:

$\mathrm{q}_{\mathrm{fd}}=\mathrm{q}_{\mathrm{f}} \gamma_{\mathrm{n}} \gamma_{\mathrm{s}}$ with $\gamma_{\mathrm{s}}, \mathrm{q}_{\mathrm{f}}, \gamma_{\mathrm{n}}$ as in the Assessment Method 2 evaluation.

This renders $q_{f d} \approx 80 \mathrm{~kg} / \mathrm{m}^{2}\left(=1520 \mathrm{MJ} / \mathrm{m}^{2}\right)$. The corresponding values for the steel temperature can be read from Fig. 3 and amount $400^{\circ} \mathrm{C}$ and $530^{\circ} \mathrm{C}$ for the columns and the spandrel beams respectively.

The (characteristic) values of the critical steel temperature $T_{c}$ can be calculated on basis of e.g. [10]. Due attention must be paid to a proper load combination for accidental design, including partial safety factors and combination coefficients. In the CIB design guide, this is left to the national authorities.Therefore, in the present analysis, current (conservative) Dutch rules are followed. It can be shown then that design values for the critical temperature $T_{c d}=T / \gamma_{\text {of }} 500$ and $850^{\circ} \mathrm{C}$ hold for the columns and spandrel beams respectively. Thus the design criterion according to equ. (4) is met. This means that - with appropriate reliability the steel frame may be assumed to withstand the anticipated fire, so that bare external steelwork is acceptable.

\section{CONCLUSIONS}

Structural fire safety requirements may render important consequences, not only in terms of building costs but, occasionally, also for the whole building concept. In traditional methods for structural fire safety design the requirements are conventional and based on global experience, which may lead to unjustified and/or uneconomic decisions.

The presentation of functional requirements which are consistent with the level of the applied verification models, is considered as the main advantage of the advanced CIB-methods for structural fire safety design, viz. CIB-Assessment Methods 2 and 3.

This paper explains some of the principles of these methods and exemplifies their application for a practical design situation, with reference to a more traditional approach. More in particular it follows from the case study that:

- the advanced CIB-design concepts provide the possibility for a functional analysis of given requirements; already in their present form they may be a useful tool in discussions with building officials on fire safety requirements;

- verification on basis of Assessment Method 3 is - e.g. regarding the probabilistic aspects - not fully operational; in situations which are more complicated than the reviewed one, this may render practical. problems.

More in general, it is emphasized that the performance of systematic case studies of the kind reviewed in this paper, is very useful because it constitutes an important means to explore the benefits and possible shortcomings of the advanced design methods. Others are therefore invited to do similar exercises and to exchange the results. 


\section{ACKNOWLEDGEMENT}

The CIB-design concept, reviewed in this paper has been developed within a workshop of the Fire Commission of the Conseil International du Bâtiment (CIB W14).

\section{REFERENCES}

[1] Magnusson, S.E. and Pettersson, 0.: "Rational design methodology for fire exposed load bearing structures", Fire Safety Journal, 3 (1981)

[2] DIN 18230: "Baulicher Brandschutz im Industriebau", Vornorm, Ber1in, 1982 .

[3] CIB/W14: "A Conceptional Approach Towards a Probability Based Design Guide on Structural Fire Safety", Fire Safety Journa1, Vo1. 6, no. 1, 1.983.

[4] CIB/W14: "Design Guide for Structural Safety", to be published in Fire Safety Journal, 2nd half 1985.

[5] Witteveen, J.: "A Systematic Approach Towards Improved Methods of Structural Fire Engineering Design", Proceedings 6th International Fire Protection Seminar organized by VFDB, Karlsruhe, 1982.

[6] Twilt, L.: "New Approach to Fire Protection in The Netherlands", Fire Safety in Buildings with Stee1, 1st International Symposium of the ECCS, The Hague, 1974.

[7] Bry1, S.: "Fire Load in Office Buildings - Fire Safety in Constructional Steelwork", Part III, ECCS-III-74-2-D.

[8] CEB/FIP: "Mode1 Code for Concrete Structures", Vo1. 1, Joint Committee on Structural Safety, Comité Euro-international du Béton, Bureau de Paris.

[9] Law, M. and O'Brien, T.: "Fire Safety of Bare External Stee1", Constrado, May 1981 .

[10] ECCS-Technical Comittee 3: "Fire Safety of Steel Structures", European. Convention for Constructional Steelwork, Elsevier Scientific Publishing Company, Amsterdam, 1983. 
